\title{
The role of the orthodontist in the early simulating plate rehabilitation of children with Down syndrome
}

\author{
Teresa Matthews-Brzozowska', Jolanta Walasz², Maja Matthews-Kozanecka', \\ Zofia Matthews ${ }^{4}$, Przemysław Kopczyński ${ }^{4}$ \\ ${ }^{1}$ Department and Clinic of Maxillofacial Orthopaedics and Orthodontics, Poznan University of Medical Sciences, Poland \\ ${ }^{2}$ Centre for Dental Techniques and Technologies at the Department of Biomaterials and Experimental Dentistry, Poznan \\ University of Medical Sciences, Poland \\ ${ }^{3}$ Department of Social Sciences, Poznan University of Medical Sciences, Poland \\ ${ }^{4}$ Centre for Orthodontic Mini-implants at the Department and Clinic of Maxillofacial Orthopaedics and Orthodontics, Poznan \\ University of Medical Sciences, Poland
}

\begin{abstract}
Introduction. Abnormalities in the oro-facial complex in children with Down syndrome can be corrected through oro-facial therapy which makes use of a palatal plate.

Aim. The aim of this study was to present the therapeutic effects of orthodontic palatal plate therapy in children with Down syndrome.

Material and methods. The study was conducted on 50 children with Down syndrome between the ages of 3 months and 2 years who were treated by means of stimulating plate therapy a period of two years.

Results. The study found that in $50 \%$ children with Down syndrome who underwent palatal plate oro-facial rehabilitation there was a visual improvement of the mimetic muscles, tongue retraction as well as lip closure.

Conclusions. The care by orthodontist and early palatal plate therapy ought to constitute an integral part of the comprehensive multidisciplinary rehabilitation of children with Down syndrome.
\end{abstract}

Key words: Down syndrome, oro-facial rehabilitation, stimulating palatal plate.

The first description of a patient with Down syndrome was presented by Jean-Étienne Dominique Esquiriol in 1838. In 1866 John Langon Down published an article in which he delineated the characteristic features of this disorder, hence the condition being named after him. Down syndrome is a disorder conditioned by the presence of an extra autosomal chromosome. The mutation involves the presence of an extra copy of chromosome 21 in a pair of autosoms. There are three types of Down syndrome. The most common type is simple trisomy 21, which accounts for $90-95 \%$ of all Down syndrome cases. Translocation trisomy is much less frequent and occurs in $5-6 \%$ of cases. The rarest form is mosaic trisomy. In people with a mosaic karyotype the characteristic features of Down syndrome are less pronounced [1, 2]. The phenotypic features of Down syndrome occur when there is triple the number of genes characteristic of chromosome pair 21, regardless of which karyotype contains an extra copy. The incidence of Down syndrome in Poland is estimated at 1 in 604 live births. Publications on the subject identify the age of the pregnant woman as one of the risk factors of this disorder [3].

Typical phenotypic features of Down's syndrome which permit clinical diagnosis after birth include hypotonia; brachycephaly; extra skin folds on the neck; 
midfacial hypoplasia (flat face); flat facial profile; widely spaced upslanting palpebral fissures; a flat nasal bridge; small misshapen ears; small wide hands with simian creases across the palms; and short stature [4]. The features which occur in the mouth include a slack, fissured and seemingly enlarged tongue; decreased tone of the orbicularis oris and buccinator muscles; and a disturbed balance of forces in the mouth with the tongue muscles being dominant. Incorrect tongue position can cause open bite, which is often diagnosed in children with Down syndrome. Because of the habitually open mouth and mouth breathing, such patients frequently develop malocclusion as well as disorders related to breathing, swallowing and articulation $[5,6,7]$. Additionally, the development of the mid-face region is inhibited [8]. In a study conducted in 1990, German researchers proved that the most severe symptom in children with Down syndrome is facial muscle hypotonia. The abnormalities and dysfunctions observed include varying degrees of mouth opening, the tongue protruding beyond the dental arches, inadequate chewing, and impaired articulation [9]. As a result of the phenomenon of neuroplasticity, which refers to the ability of the nervous system to change in response to external stimuli, manual rehabilitation exercises are typically introduced in early infancy. Such exercises help to harmonise the movements of the mandible and the tongue during sucking and swallowing, which promotes the correct development of chewing and speech functions [10]. The position of the tongue is evaluated when the child is lying down, sitting, playing, eating, drinking and speaking. A palatal plate with a stimulation element ought to be an integral part of such therapy. The aim of this study was to present a visual assessment of the facial features of children with Down syndrome made by the parents/guardians and orthodontists in order to obtain information regarding the effectiveness of oral rehabilitation through the use of a stimulating palatal plate, documented in the form of medical photographs as well as entries in examination reports and answers to questionnaire questions at twomonth intervals.

\section{Material and methods}

From among the patients who received treatment as part of the programme of orthodontic care for children with congenital craniofacial defects, a group of 50 small children with Down syndrome were selected. The children were undergoing rehabilitation through the use of a palatal plate with a stimulating element for changing tongue position. The group comprised 28 girls and 22 boys aged between 3 months and 2 years. There were 22 only children among these children with Down syndrome, 21 had a brother or sister, and the remaining 7 came from large families. Twenty seven of the children were first-borns, 18 were second children, and 5 were later in the order of births, including 2 who were born as fifth children. In addition to anamnestic and clinical examinations of the children, the research project also included the parents, who were asked to closely monitor their children's progress and provide answers to a questionnaire conducted by an orthodontist during each of the bimonthly check-ups. The questions related to observing the facial appearance and tongue position of the children with Down syndrome; the frequency and duration of palatal plate usage; the child's willingness to perform exercises; as well as other observations made by the parents/guardians at home such as, for example, excessive salivation or the duration of lip closure without the plate. There were also questions relating to the observations made by an orthodontist during the regular appointments. Palatal plates, together with the stimulation element, were replaced every 6 months so as not to inhibit the development of the jaw. The study compared the effects of using palatal plates with two types of stimulation elements.

A statistical analysis of the data collected made it possible to answer the following questions:

- Does using plates with different stimulation elements in early infancy in children with Down syndrome produce better visual treatment results than using them at an older age?

- Which type of stimulation element produces better visual results according to the parents and orthodontists?

- What is the effectiveness of a stimulating plate in children with Down syndrome when it is used irregularly and when cooperation with the parents/ guardians is inadequate?

Statistical analyses were performed using the Statistica 10.0 (StatSoft Inc., USA) program. The compatibility of the analysed quantitative variables with a normal distribution was tested by means of the Shapiro-Wilk test. For inter-group comparisons the Kruskal-Wallis test was used. A correlation analysis of the variables on the qualitative scales was performed using a chi-square test of independence. The assumed level of significance was $\alpha=0.05$. The results were considered statistically significant at $p<0.05$. 
The research was approved by the Bioethics Committee at the Poznan University of Medical Sciences (decision No 97/11).

\section{Results}

The position of the tongue was assessed in an initial examination by an orthodontist and by the parents/ guardians on a four-point scale (Table 1). In the initial assessment by the orthodontist and the parents the tongue was positioned between the lips in the majority of the children. No differences were observed in the tongue position in children of different genders $(p=0.861)$. Both in boys and in girls in the rest position the tongue was lying between the lips or between the alveolar margins (Table 2).

In 44 children the first palatal plate had a cylinder with a "roller", and 6 children had a plate with a movable bead (Table 3). Examples of plates and their application in a patient's mouth are presented in Figures 1 and 2.

An analysis of the photographic documentation collected throughout the course of the study revealed that in $86 \%$ of children with Down syndrome who received stimulating plate therapy there was a significant improvement as regards tongue position and lip closure and a resultant improvement in facial expression. The parents of 3 children temporarily withdrew from the treatment programme after using the first plate due to the need for other medical treatment, but

Table 1. Assessment of tongue position in children with Down syndrome by an orthodontist and by a parent/guardian

\begin{tabular}{lcc}
\hline \multicolumn{1}{c}{ Tongue position } & Orthodontist & Parent/Guardian \\
\hline Inside the mouth & 2 & 6 \\
\hline Between the alveolar margins & 14 & 12 \\
\hline Between the lips & 23 & 23 \\
\hline Protruding from the mouth & 11 & 9 \\
\hline
\end{tabular}

Table 2. Tongue position assessed by an orthodontist in children with Down syndrome according to gender

\begin{tabular}{lccc}
\hline \multirow{2}{*}{\multicolumn{1}{c}{ Tongue position }} & \multicolumn{3}{c}{ Gender } \\
\cline { 2 - 4 } & Boy & Girl & Total \\
\hline Inside the mouth & 1 & 1 & 2 \\
\hline Between the alveolar margins & 6 & 8 & 14 \\
\hline Between the lips & 9 & 14 & 23 \\
\hline Protruding from the mouth & 6 & 5 & 11 \\
\hline Total & 22 & 28 & 50 \\
\hline
\end{tabular}
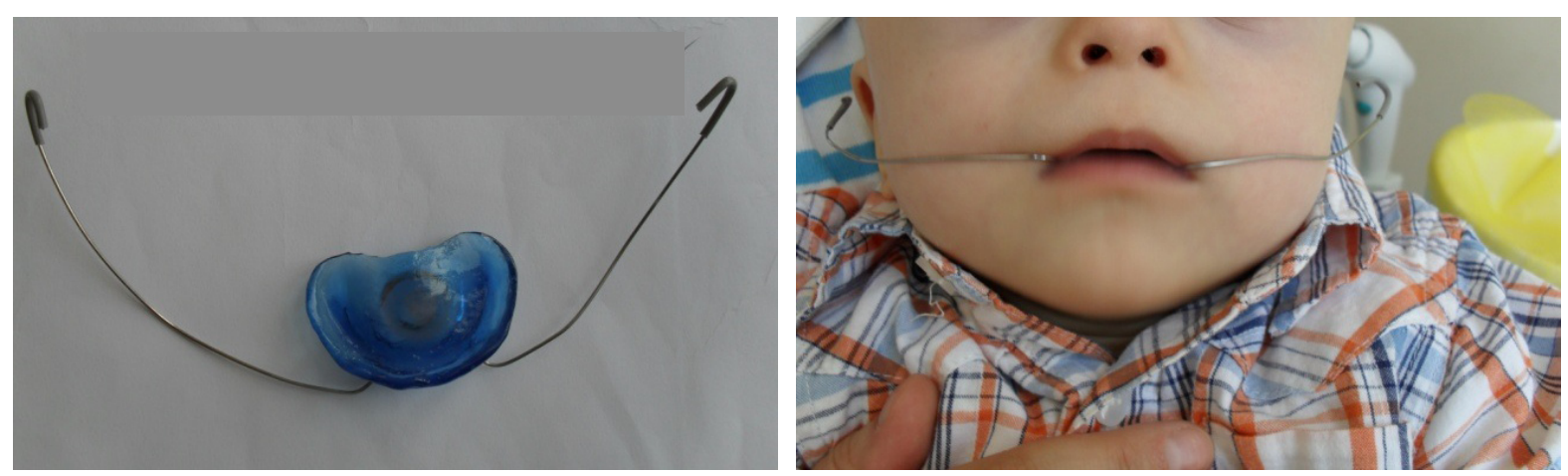

Figure 1. A palatal plate (left image) with a stimulator in the form of a cylinder with a "roller" and wire "whiskers" - patient G.S. (right image)
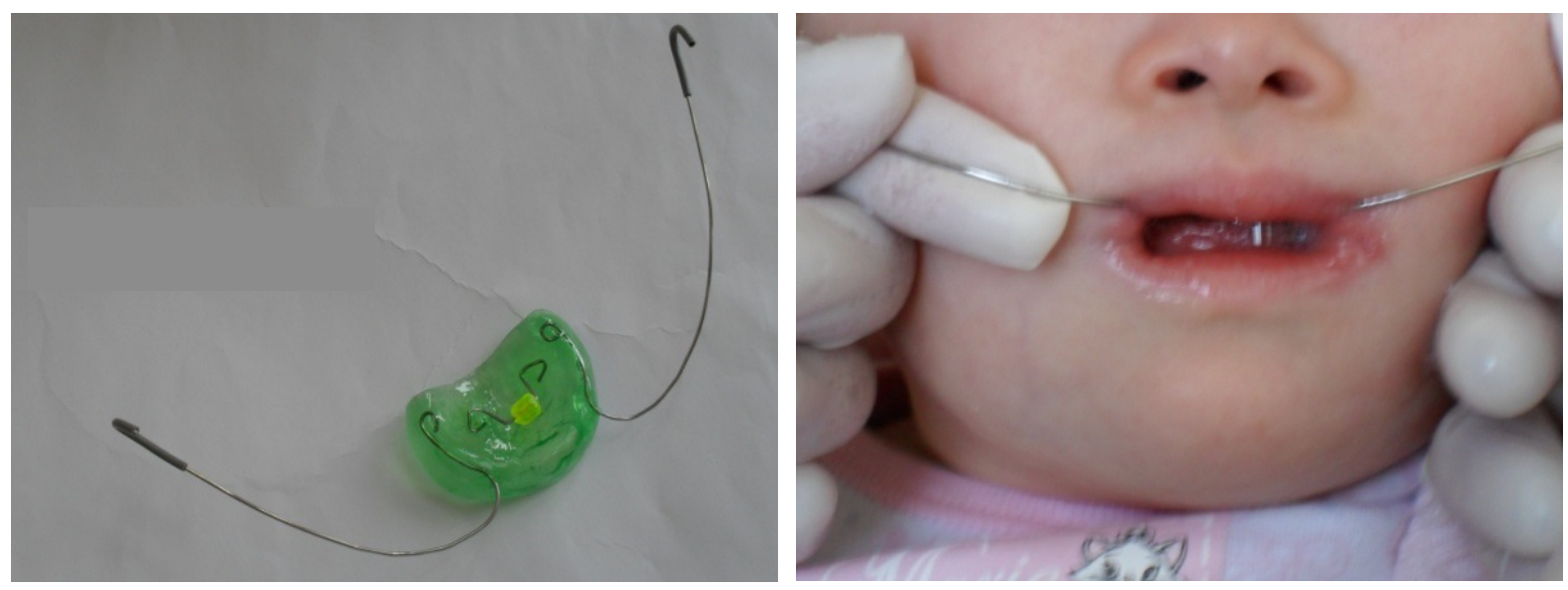

Figure 2. A palatal plate (left image) with a stimulator in the form of a movable bead and wire "whiskers" - patient B.M. (right image) 
they expressed an interest in continuing rehabilitation at a later date. After using the first plate 10 patients discontinued treatment. In the opinions of both the parents and orthodontists, in the case of 7 patients there was no marked improvement in the tongue position and mimetic muscles (Table 5).

The assessments of the type of stimulator used made by the parents/guardians and the orthodontist were mostly identical. It was observed that using a plate having a cylinder with a "roller" produced the best results as regards lip closure in 33 patients, whereas in 10 patients a movable bead was more effective. In 28 patients tongue retraction was more pronounced after using a movable bead, whereas a cylinder with a "roller" worked better in 9 children. In the case of 6 patients both stimulation elements were rated equally. Based on an analysis of photographic documentation and the opinions of the parents of the children with Down syndrome, in 40 patients a cylinder with a "roller" produced a significant visual improvement in the mimetic muscles. The study also analysed the correlation between the age of the children and the adaptation of a palatal plate. The Kruskal-Wallis test rendered a statistically significant result ( $p=0.003$ ). The Dunn's multiple comparison test indicated that there were statistically significant differences in age between the chil- dren with good plate adaptation and those who quickly became discouraged from exercises ( $p=0.002$ ). The children in whom plate adaptation was good were approximately one year old (Table 6). In the analysis of correlation between plate adaptation and the exercise routine the chi-square test rendered a statistically significant result ( $p=0.027$ ). It was demonstrated that there is a correlation between plate adaptation and the exercise routine, as well as between the duration of exercises with a palatal plate and plate adaptation $(p=0.004)$. Longer and more frequent exercises resulted in a better assessment of the results by both the parents/guardians of the children with Down syndrome and the orthodontists.

\section{Discussion}

In children with Down syndrome it is necessary to carefully observe the stomatognathic system in order to determine the best time for starting therapy, monitor its progress and assess the results. Muscular abnormalities in the oro-facial complex become apparent at birth and their manifestations include the baby's difficulty in sucking, swallowing and closing its mouth as well as tongue protrusion. The first motor responses of the oral muscles in a newborn baby are reflex responses

Table 3. Type of stimulation element in $1^{\text {st }}, 2^{\text {nd }}$ and $3^{\text {rd }}$ stimulating plate

\begin{tabular}{lccc}
\hline \multicolumn{1}{c}{ Stimulation element } & $1^{\text {st }}$ plate & $2^{\text {nd }}$ plate & $3^{\text {rd }}$ plate \\
\hline Cylinder with a "roller" & 44 & 16 & 2 \\
\hline Movable bead & 6 & 24 & 7 \\
\hline
\end{tabular}

Table 4. Position of stimulation element in $1^{\text {st }}, 2^{\text {nd }}$ and $3^{\text {rd }}$ stimulating plate

\begin{tabular}{lccc}
\hline \multicolumn{1}{c}{ Position } & $1^{\text {st }}$ plate & $2^{\text {nd }}$ plate & $3^{\text {rd }}$ plate \\
\hline Close to the front, immediately behind alveolar margin/teeth & 8 & 1 & 0 \\
\hline In the centre of the plate & 30 & 10 & 1 \\
\hline Close to the rear of the plate & 12 & 29 & 8 \\
\hline
\end{tabular}

Table 5. Improvement in tongue position and mimetic muscles in children with Down syndrome

\begin{tabular}{cc}
\hline $\begin{array}{c}\text { Has there been an improvement in tongue position } \\
\text { and mimetic muscles? }\end{array}$ & Number \\
\hline Yes & 43 \\
\hline No & 7 \\
\hline
\end{tabular}

Table 6. Correlation between a patient's age and palatal plate adaptation in children with Down syndrome over the entire course of therapy ( 2 years)

\begin{tabular}{lccc}
\hline \multicolumn{1}{c}{ Plate adaptation } & Average age & SD & p \\
\cline { 1 - 2 } Good plate adaptation & Below 1 year & 0.8 & \multirow{2}{*}{0.003} \\
\cline { 1 - 2 } Increased salivation & 1.5 years & 1.3 & \\
\cline { 1 - 2 } Rather quick discouragement of the child & Over 2 years & 0.7 & \\
\hline
\end{tabular}


to tactile stimuli. Irritation of the mouth area produces the rooting reflex, turning the head towards the stimulus and opening the mouth. Stimulating the gums produces automatic jaw movements, the so-called bite reflex $[11,12]$. It is recommended that the CastilloMorales oro-facial regulation therapy should be implemented immediately after birth. The therapy ought to be conducted under the supervision of an experienced therapist because it is a significant component of neurophysiological therapy. The treatment includes massaging by touching, stroking and stretching, as well as using the most common vibration technique $[10,13$, 14]. A child who starts to receive this therapy from the earliest stages of life can develop motor patterns which are close to the norm. This principle is the basis of functional maxillofacial orthopaedics and the effects clearly confirm the validity of such an assumption [15].

In addition to the manual stimulation of certain areas of the face, another method of oro-facial rehabilitation is a therapy which makes use of individual stimulating palatal plates, vestibular plates or other orthodontic appliances. Such forms of treatment promote an increase in the activity of the muscles responsible for swallowing, chewing and articulation. The rehabilitation treatment is adjusted to the individual needs of each patient, depending on the severity of the defect and any concurrent medical conditions. The therapy can include two components (massage and an appliance) or only one. Out of the patients analysed in the present study 33 children with Down syndrome underwent therapy consisting of both components, and those children achieved better results in the visual assessment of facial appearance over the period of two years $[12,16]$.

At every stage of therapy it was essential to cooperate closely with the children's parents and to motivate them to become involved and to carefully monitor the effects of treatment, as the ultimate outcome of the therapy largely depended on them, which has also been stressed by other researchers [17]. The parents of these children with Down syndrome were aged between 25 and 49, and the majority were between 31 and 40 years old. The average age of the mother when giving birth to a baby with Down syndrome was 35 years; and this was slightly lower than the age of the father which was 36 years. This data is consistent with the reports by Klotzka and Trojnarska, in whose study the age of the parents of children with Down syndrome confirmed the assertion that the probability of this anomaly is greater in the case of older mothers [18]. Hennequin et al. showed that the risk of Down syndrome is higher in the first pregnancy than in subsequent pregnancies, but also in later ones when there is a long interval between pregnancies [5].

Two important elements in the visual assessment of a child with Down syndrome are tongue position and lip muscle tone, which affect the facial features and play a considerable part in how the child is perceived by other people, which has been described by numerous researchers $[9,11,19]$. In this study only two children with Down syndrome were able to fully retract the tongue into the oral cavity, which confirms that it is the parents of children with an incorrect tongue position that bring their children for treatment. This coincides with the findings obtained by Fischer-Brandies et al. in 1988, as well as Hohoff and Ehmer in 1999. Those researchers observed a correct tongue position in about $5 \%$ of children with Down syndrome between the ages of 1 month and 6 years. This study did not discover significant differences in tongue position in the children with Down syndrome depending on gender when comparing its position during the initial examination, as well as during and after rehabilitation on the basis of the photographic documentation produced for every visit. An improvement in the mimetic muscles and tongue position was achieved in 43 out of the 50 analysed patients with Down syndrome. This result is higher than that reported by Hohoff et al., where improvement in tongue position was observed in $65 \%$ of patients; and by Schuster et al., where an improvement was recorded in 55\% of patients treated with a stimulating plate $[19,20,21]$. The findings are similar to the findings of earlier studies conducted in Poland by Radwańska and Żmuda-Stawowiak, who reported an improvement in 45 out of the 55 patients who had received treatment [22]. Improvement was also recorded in 68 children in a study by Zavaglia et al., as well as in 42 children with Down syndrome aged between 6 and 21 months in a study by Bäckman et al., where there was significant improvement in respect of almost all the parameters in comparison to the initial condition [23, 24].

In almost all the children, inserting a palatal plate triggered the reaction described by Fisher-Brandies and Avalle, Limbrock et al., Nęcka et al., Matthews-Brzozowska et al., which involved retracting the tongue into the mouth and raising it towards the stimulation element located at a specific place on the palatal plate, which resulted in bringing the lips closer together and making it possible to close the mouth. The children who had the best plate adaptation in this study were the youngest group, around 12 months old [12, 25, 
26]. Good plate adaptation in the youngest children was observed earlier by Schuster and Giese, thus it can be stated that introducing systematic rehabilitation of children at the youngest possible age can increase the chances of good palatal plate adaptation [19]. The parents reported that their children became discouraged from exercises when their teeth started to erupt, which was also observed by Bäckman et al. [27]. They also declared that the improved muscle tone continued after the plate had been removed, which was confirmed by Krombacher et al., who conducted long-term observations of children with Down syndrome who had undergone early oro-facial therapy through the use of a palatal plate [14].

Good plate adaptation was usually connected with performing the exercises correctly and systematically, which required a considerable involvement of the parents/guardians. However, it has to be borne in mind that though the parents or legal guardians may become fully involved in the therapy and accept it, they also have the right to discontinue rehabilitation. Thus it is extremely important to clearly explain to them what the treatment involves and what its results are likely to be. If the expectations of the parents/guardians are different, their involvement may turn out to be inadequate [28]. It was observed that among the patients who were doing the palatal plate exercises correctly and systematically, 19 children with Down syndrome $(65 \%)$ were also undergoing manual therapy according to the Castillo-Morales method, thus the involvement of the parents/guardians in the rehabilitation of their children was evident.

This study also analysed the different elements of a stimulating palatal plate and their influence on tongue position and lip closure, as well as a visual improvement in the mimetic muscles. The assessments of the type of stimulator used made by the parents/ guardians and the orthodontist were mostly identical. It was observed that using a plate with a cylinder with a "roller" produced the best results as regards lip closure in 33 patients. Tongue retraction was more pronounced in 28 patients with Down syndrome after using a movable bead. Based on an analysis of photographic documentation and the observations of the parents of the children with Down syndrome, in 40 patients a cylinder with a "roller" produced a significant visual improvement in the mimetic muscles. Thus it can be stated that a stimulator in the form of a movable bead, used mostly in the $2^{\text {nd }}$ and $3^{\text {rd }}$ plate, had the greatest impact on tongue position and retraction; whereas a cylinder with a "roller" had a greater influ- ence as regards lip closure and a visual improvement in the appearance of the mimetic muscles. In part (63\%), these findings are consistent with the data published by Castillo-Morales in 1992.

To recapitulate, oro-facial therapy has a significant impact as regards tongue position and lip closure, as well as a visual improvement in the mimetic muscles. Children with Down syndrome who began stimulating plate therapy in infancy in a considerable number of cases achieved a visual improvement in the mimetic muscles.

\section{Conclusion}

The results from oro-facial stimulating plate therapy obtained in this study clearly demonstrate that this method, together with the substantial involvement of an orthodontist, plays a crucial role in the rehabilitation of children with Down syndrome.

\section{References}

1. Neuhauser M, Krackow S. Adaptive-filtering of trisomy 21: risk of Down syndrome depends on family size and age of previous child. Naturwissenschaften. 2007;2:117-21.

2. Pietrzak P, Kowalska E. Możliwości leczenia ortodontyczno-ortopedycznego pacjentów z zespołem Downa na podstawie piśmiennictwa i obserwacji własnych. Pediatr Pol. 2012;626-32.

3. Kucharczyk M, Goryluk-Kozakiewicz B, Kuguado M, Gutowska A, Borucka-Mankiewicz M, Krajewska-Walasek M. Prenatal detection using MLPA method of a de novo translocation Down syndrome in a male foetus. Fac Univ Palacky Olomouc Czech Repub. 2012;156(Supl. 2):101-16.

4. Roizen NJ, Patterson D. Down's syndrome. Lancet. 2003; 361:1281-9.

5. Hennequin M, Veyrune JL, Bourdiol P. Signitificance of oral health in person with Down syndrome. Dev Med Child Neurol. 1999;41:275-83.

6. Matthews-Brzozowska T, Nęcka A. Zaburzenia czynnościowe w układzie stomatognatycznym u pacjentów z zespołem Downa. Ann UMCS. 2007;62(18):408-21.

7. Oliveira A, Paiva S, Campos M, Czeresnia D. Factors associated with malocclusions in children and adolescents with Down syndrome. Am J Orthod Dentofacial Orthop. 2008;133(4):489-98.

8. Lopez-Perez RS, Borges-Yanez A, Lopez-Morales P. Anterior open bite and speech disorders in children with Down syndrome. Angle Orthod. 2008;78:221-7.

9. Faulks D, Mazille MN, Veyrune JL, Hennequin M. Masticatory dysfunction in persons with Down's syndrome. J Oral Rehabil. 2008;35(11):863-9.

10. Nęcka A, Regner A, Matthews-Brzozowska T. Ustno-twarzowa terapia regulacyjna (Uttr) według koncepcji Castillo-Moralesa. Dent Med Probl. 2004;41(3):537-42.

11. Castillo-Morales R. Die orofaziale Regulationstherapie. Kommunikation. Plafum Verlag Munchen. 1992;44-6. 
12. Limbrock GJ, Castillo-Morales R, Hoyer H, Stöver B, Onufer C. The Castillo-Morales approach to orofacial pathology in Down syndrome. Int J Orofacial Myology. 1993; 19:30-7.

13. Pecyna MB, Sadowska L. Ocena psychofizjologiczna dzieci z zespołem Downa stymulowanych od urodzenia metodą odruchowej lokomocji. Zdr Publ. 2000(6): 205-10.

14. Korbmacher H, Schwan M, Berndsen S, Bull J, Kahl-Nieke B. Evaluation of a new concept of myofunctional therapy in children. Int J Orofacial Myology. 2004;30:39-52.

15. Jung M, Nahm D, Yang W. Effects of upper lip closing force on craniofacial structures. Am Orthod Dentofacial Orthop. 2003;123:58-63.

16. Hohoff A, Ehmer U. Short-term and long-term results after early treatment with the Castillo Morales stimulating plate. A longitudinal study. J Orofac Orthop. 1999; 60(1):2-12.

17. Jamroszczyk K, Górniak D, Lipski M, Buczkowska-Radlińska J, Trusewicz M. Postępowanie z pacjentami upośledzonymi umysłowo i dotkniętymi wrodzonymi wadami rozwojowymi w czasie leczenia ortodontycznego. Ann Acad Med Stetin. 2008;54(1):112-7.

18. Klotzka A, Trojnarska O. Leczenie wrodzonych wad serca u pacjentów z zespołem Downa. Pol Prz Kardiol. 2009; 11(4):292-5.

19. Schuster G, Giese R. Retrospective clinical investigation of the impact of early treatment of children with Down syndrome according to Castillo-Morales. J Ortofac Orthop. 2001;62(4):255-63.

20. Fischer-Brandies $\mathrm{H}$, et al. Early treatment of orofacial pathology in Down's syndrome. Monatsschr Kindereheilkd. 1984;132:620-1.

21. Hohoff A, Ehmer M. Kurzzeit und Stimulationsplatte nach Castillo-Morales. J Orofac Orthop. 1999;60:2-12.

22. Radwańska E, Żmuda-Stawowiak D. Rehabilitacja układu stomatognatycznego u dzieci z zespołem Downa. Mag Stomat. 2000;4:58-60.
23. Zavaglia V, Nori A, Mansour N. Long term effects of the palatal plate therapy for the orofacial regulation in children with Down syndrome. J Clin Pediatr Dent. 2003;28(1):89-93.

24. Bäckman B, Grevér-Sjölander A, Bengtsson K, Persson J, Johansson I. Children with Down syndrome: oral development and morphology after use of palatal plates between 6 and 48 months of age. Int J Paediatr Dent. 2007;17(1):19-28.

25. Fischer-Brandies H, Avalle C. Die Auswirkung der systematischen kieferortopadischen Frunhebandlung bei Trisomie 21. Fortschr Kieferort. 1988;(49):695-703.

26. Matthews-Brzozowska T, Walasz J, Matthews Z. Zespół Downa - Wczesna terapia płytka stymulacyjną Castillo-Moralesa. Now Lekare. 2009;3-4(78):253-5.

27. Bäckman B, Grever-Sjolander AC, Holm AK, Johansson I. Children with Down syndrome: oral development and morphology after use of palatal plates between 6 and 18 months of age. Int J Pediatr Dent. 2003;13:327-35.

28. Sitarska-Haber A, Jędrzejowski A. Świadoma zgoda uczestnika na udział w badaniu klinicznym - co badacz wiedzieć powinien. Stand Med, Pediatr. 2012;9:233-41.
Correspondence address: Przemysław Kopczyński Centre for Orthodontic Mini-implants Poznan University of Medical Sciences 70 Bukowska Street 60-812 Poznań, Poland email: pkopczynski@orto1.net phone: +48 602471666 